\title{
Research on the Coordinated Development of Beijing's Culture Industry and Tourism Industry Based on the Coupling Analysis Method
}

\author{
Gang FANG ${ }^{1, a}$, Tian-yi LI ${ }^{1, b}$ \\ ${ }^{1}$ Business school, Beijing Institute of Fashion Technology, Beijing, China
}

\begin{abstract}
At the stage where China's economic growth has shifted from high speed to high quality, how to build a sustainable development system with complementary high-quality resources through the integration of culture and tourism industries is the core issue. Since the 26 proposals for the integration of Beijing's culture and tourism industries were put forward, Beijing is gradually building a sample of integrated culture and tourism development. In this paper, the theory of physics coupling is applied to the research on industrial integration, and a comprehensive evaluation index system is formulated. At the same time, the relative development model, coupling degree model, and coupling coordination degree model were used to empirically analyze the integrated development of the culture and tourism industries in Beijing from 2005 to 2017. The research results show that the degree of coupling and coordination of Beijing's culture and tourism industry experienced three phases of mild imbalance, primary coordination, moderate coordination during the statistical period, and the integration effect gradually improved. Based on this, this article puts forward policy suggestions that are conducive to the further coordinated development of Beijing's culture industry and tourism industry.
\end{abstract}

\section{Introduction}

In recent years, the integrated development of culture industry and tourism industry is gradually becoming an important way to deepen the supply-side reform. Beijing has advantaged culture resources and historical deposits. During the past 40 years of reform and opening up, Beijing's culture and tourism industries have been greatly developed, with various infrastructure facilities gradually improved, a prosperous and active market, and increasingly extensive foreign exchanges. In the new era of economic development, Beijing took the lead in proposing normative documents to promote the integration of culture and tourism industries, and vigorously promoting the indepth integration of the innovation-driven culture and tourism industry. In addition, in the academic field, the integrated development of industry has gradually become a research focus. However, there are few studies on the integration of culture and tourism industries in Beijing. What is the development stage of the integration of culture and tourism industry in Beijing? What aspects should be paid attention in the future development? Exploring these two questions is of great significance to the sustainable development of Beijing's culture tourism industry.

\section{Research design}

Bao Hongjie and Wang Shengpeng (2010) pointed out that coupling refers to the dynamic correlation process in which the elements in a complex system make the system change from disorder to order through mutual influence. In this process, the interactive relationship formed between the subsystems is called the coupling relationship ${ }^{[1]}$.

\subsection{Indicator Construction and Data Sources}

Considering the representativeness of elements and the availability of data, this paper divides the comprehensive development level of culture industry and tourism industry into four dimensions: industrial scale, human resources, factor supply, and market efficiency. In each dimension, by drawing on the basis of the division of the predecessors and comprehensively considering the development law of the culture tourism industry in Beijing, this paper finally established 15 indicators for the comprehensive development of the culture industry and 12 indicators for the comprehensive development of the tourism industry. In addition, the data in this article comes from the Beijing Municipal Bureau of Statistics and the Beijing Basic Database for Macroeconomic and Social Development.

\subsection{Data Processing}

Since the data of each dimension in the index system established in this study differs in units and magnitudes, it may have an impact on the later calculation results. Therefore, this paper firstly carried out a dimensionless 
quantization process on the original data. At the same time, considering that the indicators of each dimension have different degrees of impact on the overall development of the industry, this study uses the entropy method to determine the weight of each dimension.

In the culture and tourism industry development index system established in this paper, all dimensions have a positive impact on the overall system. Based on this, the dimensionless quantitative calculation formula is:

$$
\begin{aligned}
& \beta_{i j}=\frac{x_{i j}-\min \left(x_{i j}\right)}{\max \left(x_{i j}\right)-\min \left(x_{i j}\right)} \\
& \beta^{\prime}{ }_{i j}=\beta_{i j}+0.01
\end{aligned}
$$

In the formula, xij represents the original data of the $\mathrm{j}$ th index in the i-th year. The maximum and minimum values of each original index are expressed by $\max (x \mathrm{ij})$ and $\min (x i j)$, respectively. The calculated result $\beta_{\mathrm{ij}}$ is the data after the dimensionless quantization target. Since the subsequent operations involve taking logarithms, in order to avoid meaningless situations in logarithmic calculations, this paper refers to the processing methods of previous scholars and optimizes the original dimensionless quantitative calculation formula, increasing $\beta_{\mathrm{ij}}$ by 0.01 , and the resulting $\beta^{\prime}$ ij is the final standardization data.

In the current research, most scholars use the entropy method to determine the weight of each sub-index in the index system. The calculation process of the weight determined by the entropy method is as follows. First, calculate the proportion $B_{i j}$ of the index $j$ in year $i$. Secondly, the entropy value $\varepsilon_{\mathrm{j}}$ of each index is calculated by using the specific gravity obtained in the previous step. In the next step, the entropy value $\varepsilon_{\mathrm{j}}$ is substituted into formula
(5) to calculate the difference coefficient $V_{j}$ of each index. Finally, the ratio of the $\mathrm{j}$-th index difference coefficient to the total index is the weight of the $\mathrm{j}$-th index, which is expressed by $\omega_{\mathrm{j}}$ in equation (6).

$$
\begin{aligned}
B_{i j} & =\frac{\beta^{\prime}{ }^{\prime}{ }^{m}}{\sum_{i=1}^{m} \beta^{\prime}{ }_{i j}} \\
\mathcal{E}_{j} & =\frac{-1}{\ln m} \times \sum_{i=1}^{m}\left(B_{i j} \times \ln B_{\mathrm{ij}}\right) \\
\mathrm{V}_{\mathrm{j}} & =1-\varepsilon_{\mathrm{j}} \\
\varpi_{j} & =\frac{\mathrm{V}_{j}}{\sum_{j=1}^{n} \mathrm{~V}_{j}}
\end{aligned}
$$

Through the above calculation, the comprehensive evaluation index system of Beijing's culture industry and tourism industry and the weight of each index can be obtained. Among them, Table 1 is the comprehensive evaluation index system of the culture industry. The industrial scale, human resources, factor supply, and market benefits account for $0.252368,0.139147,0.408647$, and 0.199837 respectively. At the same time, the weights of the four dimensions of tourism industry scale, human resources, factor supply, and market benefits are 0.316379 , $0.155498,0.286388$, and 0.241735 , respectively. The

\begin{tabular}{|c|c|c|c|}
\hline Target layer & System layer & Indicator layer & Weights \\
\hline \multirow{15}{*}{$\begin{array}{l}\text { Comprehensive } \\
\text { development of } \\
\text { culture industry }\end{array}$} & \multirow[b]{4}{*}{ Industry scale } & C1 Museum Income & 0.090611 \\
\hline & & C2 Total number of files & 0.045293 \\
\hline & & C3 Library Total Collection & 0.050567 \\
\hline & & C4 Number of culture relics & 0.065897 \\
\hline & \multirow[b]{3}{*}{ Human Resources } & C5 Museum employees & 0.048198 \\
\hline & & C6 Number of employees in public libraries & 0.042384 \\
\hline & & $\begin{array}{l}\text { C7 Number of people employed in mass art } \\
\text { museums and culture centers }\end{array}$ & 0.048566 \\
\hline & \multirow[b]{4}{*}{ Factor supply } & C8Number of archives Number & 0.161136 \\
\hline & & C9 Number of museums & 0.033863 \\
\hline & & C10 Number of public libraries & 0.018226 \\
\hline & & $\begin{array}{l}\text { C11 Number of mass art centers and culture } \\
\text { centers }\end{array}$ & 0.195422 \\
\hline & \multirow[b]{4}{*}{ Market benefit } & C12 Museum visits & 0.075004 \\
\hline & & C13 Books and Documents Loan Times & 0.042004 \\
\hline & & C14 Use of file data & 0.051146 \\
\hline & & C15 culture activities & 0.031683 \\
\hline
\end{tabular}
analysis shows that the scale of the tourism industry plays an important role in its overall development. In contrast, factor supply plays a key role in the development of culture industries.

Table1. Beijing Culture Industry Comprehensive Evaluation Index System and Index Weights

Table2. Beijing Tourism Industry Comprehensive Evaluation Index System and Index Weights

\begin{tabular}{|l|l|l|l|}
\hline Target layer & System layer & Indicator layer & Weights \\
\hline \multirow{5}{*}{} & & C1 Domestic tourism income & 0.093990 \\
\cline { 3 - 4 } & & C2 Tourism foreign exchange income & 0.042962 \\
\cline { 2 - 4 } & C3 Number of domestic tourists & 0.100791 \\
\cline { 2 - 4 } & Industry scale & C4 Number of inbound tourists & 0.078635 \\
\cline { 2 - 4 } & \multirow{3}{*}{ Human Resources } & C5 Number of employees in travel agencies & 0.101638 \\
\cline { 2 - 4 } & C6 Star hotel employees & 0.053860 \\
\hline
\end{tabular}




\begin{tabular}{|l|l|l|l|}
\cline { 2 - 4 } & & C7 Number of travel agencies & 0.119244 \\
\cline { 3 - 4 } $\begin{array}{l}\text { Comprehensive } \\
\text { development of } \\
\text { the tourism }\end{array}$ & Factor supply & C8 Number of star hotels & 0.108573 \\
\cline { 3 - 4 } industry & Market benefit & C10 Travel agency operating income & 0.058571 \\
\cline { 3 - 4 } & & C11 Star hotel operating income & 0.113352 \\
\cline { 3 - 4 } & C12 A-level scenic spot operating income & 0.044898 \\
\hline
\end{tabular}

\section{Empirical analysis}

\subsection{The relative development model of culture industry and tourism industry}

The elements in the culture industry and the tourism industry influence each other, and they form an organic system. In addition, there are exchanges and interactions between the two industries ${ }^{[2]}$. In order to consider the coupling relationship between the two industries, we must first establish a comprehensive evaluation function for the culture industry and the tourism industry. In equation (7), the comprehensive evaluation function of the two industries can be obtained by the weighting method. Among them, $\mathrm{S} 1$ is the comprehensive evaluation function of tourism industry; S2 is the comprehensive evaluation function of culture industry. Figure 1 shows the comprehensive development level of Beijing's tourism and culture industries from 2005 to 2017. The Beijing tourism industry comprehensive development index showed an upward trend during the statistical period, and the overall development situation was good. In comparison, the trend of the comprehensive development index of the culture industry can be roughly divided into two stages. From 2005 to 2011, the development of the culture industry was relatively slow, and the development index showed a downward trend of fluctuations. From 2011 to 2017, the development trend of the culture industry was relatively good, and the overall trend was a significant upward trend.

$$
\mathrm{S}_{\mathrm{t}}=\sum_{j=1}^{n} \varpi_{j} \times \beta_{i j}^{\prime} \quad(\mathrm{t}=1,2)
$$

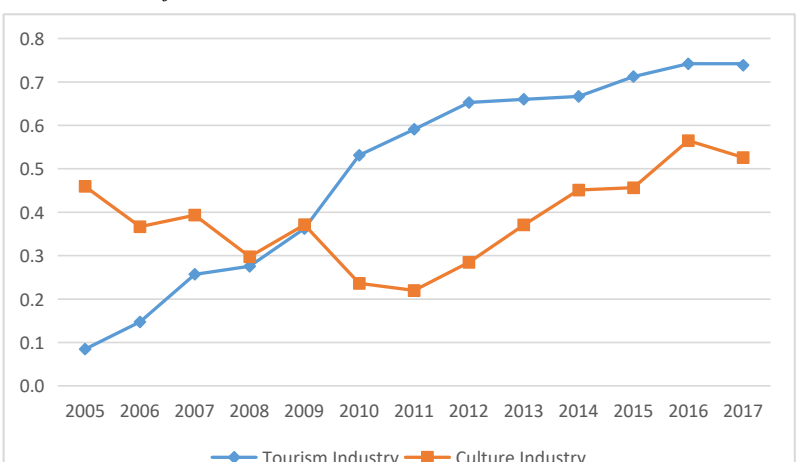

Fig1. Culture Industry and Tourism Industry Comprehensive Development Level Index

In addition, this article introduces a relative development model to explore the development differences between the two industries. In formula (8), $\mathrm{P}$ represents the relative development index of tourism industry and culture industry. The index can reflect the synchronization of the development of the tourism industry and culture industry. Here, the text divides the value range of $P$. When the $\mathrm{P}$ value is greater than 1.1, the development level of tourism is prior to the culture industry, which is called the culture lag type; when the $\mathrm{P}$ value is less than 0.9 , the development of tourism is lagging, and this situation is called the tourism lag type. In addition, when the $P$ value is between 0.9 and 1.1 , it can be regarded as the simultaneous development of the culture industry and tourism industry, which belongs to the synchronous development type. It can be seen from Table 3 that from 2005 to 2007, the development level of the tourism industry lags behind that of the culture industry. Subsequently, the development level of the two was relatively balanced between 2008 and 2009. The hosting of the 2008 Beijing Olympic Games not only drove the economic growth of the Beijing area, but also played a significant role in promoting the tourism and culture industries. From 2010 to 2017, the development speed and development level of the tourism industry increased significantly. Among them, the development gap of the culture and tourism industry from 2010 to 2013 is relatively large, and the $\mathrm{P}$ values of these three years are all greater than 2 . The results show that the nature of the tourism industry makes its development affected by international events with long-term and significant characteristics. From 2013 to 2017, the relevant state departments gradually increased their support for the culture industry. The awakening of the national culture awareness also injected new vitality into the development of the culture industry, and the gap between the culture industry and the tourism industry was gradually narrowed.

$$
P=S_{1} / S_{2}
$$

Table3. Relative development of tourism industry and culture industry

\begin{tabular}{|l|l|l|l|c|}
\hline Year & S1 & \multicolumn{1}{|l|}{ S2 } & P Value & Lag Type \\
\hline 2005 & 0.084794 & 0.459569 & 0.184507 & Tourism industry lagging \\
\hline 2006 & 0.147423 & 0.366633 & 0.402100 & Tourism industry lagging \\
\hline 2007 & 0.257070 & 0.393298 & 0.653627 & Tourism industry lagging \\
\hline 2008 & 0.275553 & 0.297599 & 0.925918 & Synchronous development \\
\hline 2009 & 0.362434 & 0.371271 & 0.976198 & Synchronous development \\
\hline 2010 & 0.531127 & 0.236259 & 2.248066 & Culture industry lagging \\
\hline 2011 & 0.590990 & 0.219873 & 2.687865 & Culture industry lagging \\
\hline
\end{tabular}




\begin{tabular}{|l|l|l|l|l|}
2012 & 0.652736 & 0.284626 & 2.293313 & Culture industry lagging \\
\hline 2013 & 0.660134 & 0.370654 & 1.780997 & Culture industry lagging \\
\hline 2014 & 0.666673 & 0.451146 & 1.477732 & Culture industry lagging \\
\hline 2015 & 0.712416 & 0.456362 & 1.561076 & Culture industry lagging \\
\hline 2016 & 0.741840 & 0.564943 & 1.313124 & Culture industry lagging \\
\hline 2017 & 0.738540 & 0.526026 & 1.404001 & Culture industry lagging \\
\hline
\end{tabular}

\subsection{Coupling model and coupling coordination model}

Referring to the evaluation methods of previous scholars, this article introduces the concept of physics coupling degree, which is used to measure the mutual relationship and role between Beijing's culture industry and tourism industry ${ }^{[3]}$. First, calculate the coupling degree of the two industries. The coupling degree in formula (9) is represented by D. By substituting the comprehensive index value $\mathrm{S} 1$ of the tourism industry in the i-th year and the comprehensive index value S2 of the culture industry, the coupling degree of the two industries in the current year can be obtained. Further, considering the limitations of the coupling model, the results may differ from the actual situation. Therefore, this article introduces the coupling coordination model. The coupling coordination model must first determine the comprehensive coordination index between the two industries, see formula (10). The comprehensive coordination index $\mathrm{T}$ in the formula consists of tourism industry and culture industry development levels S1, S2 and undetermined coefficients $\eta, \kappa$. Considering that Beijing's culture industry and tourism industry occupy the same position in all industries of its national economy, and by referring to the literature, it can be seen that most previous studies believe that these two industries are of equal importance ${ }^{[4]}$. In view of this, the value of the undetermined coefficients $\eta$ and $\kappa$ in formula (10) is specified as 0.5. Furthermore, the coupling coordination degree $\mathrm{R}$ of the culture industry and the tourism industry can be obtained by formula (11).

According to previous research conclusions, this paper divides the coupling degree into four stages: budding stage, starting stage, development stage, and maturity stage ${ }^{[5]}$. According to calculations, Beijing's culture industry and tourism industry are in the initial stage of coupling from 2005 to 2017. The characteristic of this stage is that the development of the culture industry is gradually affecting the development of the tourism industry. The coupling coordination degree reflects the degree of coordinated development of the two industries, and the coupling coordination degree $\mathrm{R}$ ranges from $0-1$. The closer value is to 1 , the stronger the synergy between the two industries in the coupled system. A good coupled system is conducive to the formation of complementary resources between the two industries and promotes the optimization and upgrading of industries. On the contrary, the value of the coupling coordination degree $\mathrm{R}$ is close to 0 , indicating that the synergy between the development of the two industries is low, the industry development is dysregulated, and the coefficient is in an unstable development stage. Referring to the research by Bi Guohua et al. (2017), this paper divides the coupling coordination index $\mathrm{R}$ into six types, as shown in Table $5^{[6]}$. From the calculation results of the coupling coordination degree type, it can be seen that during the period 2005-2017, the development of the coupling system formed by Beijing's culture industry and tourism industry has roughly gone through three stages. First, from 2005 to 2008, Beijing's culture industry and tourism industry were in a stage of slight imbalance. At this stage, there is a great deal of instability in the coordinated development of the culture industry and the tourism industry. The conclusion is basically consistent with the relative development of the two industries calculated above. The reason for the analysis is that during this period, the development of the tourism industry lags behind. There is a certain difference between the two industries in terms of resource endowment and market performance. Second, during the period 2009-2013, the type of coupling coordination between the tourism industry and the culture industry is preliminary. This stage is manifested by the substantial growth of the tourism industry, which has driven the optimization and upgrading of the culture industry. In the third stage, the coupling between the tourism industry and the culture industry has reached a moderate coordination state. At this time, the coordination effect of the two has gradually improved, forming a coupling system with complementary advantages.

$$
\begin{aligned}
& D=\frac{\sqrt{S_{1} \times S_{2}}}{S_{1}+S_{2}} \\
& T=\eta S_{1}+\kappa S_{2} \\
& R=\sqrt{D T}
\end{aligned}
$$

Table4. Types of tourism industry and culture industry development coordination

\begin{tabular}{|c|c|c|c|c|}
\hline Year & $\begin{array}{c}\text { Coupling degree } \\
\text { D }\end{array}$ & T value & Coordination R & Type of coordination \\
\hline 2005 & 0.362634 & 0.272181 & 0.314169 & Mild disorder \\
\hline 2006 & 0.452260 & 0.257028 & 0.340945 & Mild disorder \\
\hline 2007 & 0.488908 & 0.325184 & 0.398729 & Mild disorder \\
\hline 2008 & 0.499630 & 0.286576 & 0.378394 & Mild disorder \\
\hline 2009 & 0.499964 & 0.366852 & 0.428267 & Preliminary coordination \\
\hline 2010 & 0.461615 & 0.383693 & 0.420854 & Preliminary coordination \\
\hline 2011 & 0.444558 & 0.405432 & 0.424544 & Preliminary coordination \\
\hline 2012 & 0.459831 & 0.468681 & 0.464235 & Preliminary coordination \\
\hline 2013 & 0.479878 & 0.515394 & 0.497319 & Preliminary coordination \\
\hline 2014 & 0.490618 & 0.558910 & 0.523652 & Moderate coordination \\
\hline
\end{tabular}




\begin{tabular}{|l|l|l|l|l|}
2015 & 0.487854 & 0.584389 & 0.533944 & Moderate coordination \\
\hline 2016 & 0.495398 & 0.653391 & 0.568936 & Moderate coordination \\
\hline 2017 & 0.492889 & 0.632283 & 0.558252 & Moderate coordination \\
\hline
\end{tabular}

Table5. Standards for dividing coupling and coordination

\begin{tabular}{|c|c|c|c|}
\hline Coupling degree D & Coupling phase & Coordination R & Type of coupling coordination \\
\hline $0<\mathrm{D} \leq 0.3$ & Budding stage & $0<\mathrm{R} \leq 0.2$ & Severe disorder \\
\hline $0.3<\mathrm{D} \leq 0.5$ & Initial stage & $0.2<\mathrm{R} \leq 0.3$ & Moderate disorder \\
\hline $0.5<\mathrm{D} \leq 0.8$ & Progression stage & $0.3<\mathrm{R} \leq 0.4$ & Mild disorder \\
\hline $0.8<\mathrm{D} \leq 1$ & Mature stage & $0.4<\mathrm{R} \leq 0.5$ & Preliminary coordination \\
\hline & & $0.5<\mathrm{R} \leq 0.7$ & Moderate coordination \\
\hline & & $0.7<\mathrm{R} \leq 1$ & Quality coordination \\
\hline
\end{tabular}

\section{Conclusion}

Based on the relative development model, coupling model and coupling coordination model, this paper empirically analyzes the coordinated development between the culture industry and tourism industry in Beijing. The results show that there are some differences between tourism industry and culture industry. From 2005 to 2007, the development of tourism industry lagged behind that of culture industry. In the following two years, the development of tourism industry was basically the same. From 2010 to 2017, the tourism industry developed rapidly. In contrast, the development level of culture industry is relatively backward. In addition, the coupling degree of the culture and tourism industry in Beijing is low, reflecting that the correlation degree between the two needs to be improved, and it is in the initial stage of coupling between 2005 and 2017. During this period, the synergies between the development of culture industry and tourism industry have undergone three stages: mild disorder, preliminary coordination and moderate coordination. With the development of culture industry and tourism industry year by year, the coupling system jointly constituted by them is gradually optimized, and a virtuous cycle of high-quality complementarity is gradually formed in this process. In general, the imbalance between the development of culture industry and tourism industry is the main reason that restricts their coordinated development. At the same time, the active measures of the government and the industrial upgrading provide the impetus for the optimization of the coupling system.

To improve the integration quality of culture industry and tourism industry requires the joint efforts of macro and micro levels. First of all, the government should pay attention to the top-level design of the development of culture industry and tourism industry, refine the needs of industrial development, and deepen the layout and system reform of industrial parks. We will increase support for key culture and tourism enterprises and provide strong financial support and tax protection for small and mediumsized enterprises. We will pay attention to the protection of intellectual property rights, gradually establish a sound regulatory system and industrial standards, and increase punishment for enterprises that violate the rules. At the same time, we will strengthen the construction of supporting facilities and pay attention to the protection of culture and historical resources. In addition, the highquality development of the culture tourism industry is also inseparable from personnel allocation and technical innovation. Therefore, the cultivation of talents in colleges and universities should be strengthened to export more high-quality human resources for the culture industry and tourism industry. At the same time, it will promote the integration of artificial intelligence technology, big data, culture industry and tourism industry, and build a highstandard culture and tourism industry integration system. It pays attention to complementary industrial advantages and resources, and combines the unique historical and culture resources of Beijing area with tourism demands. In addition, attention should be paid to foreign exchanges and the integrated layout of Beijing-Tianjin-Hebei to further open up the space for industrial development.

At the micro level, both culture and tourism enterprises should seize the new opportunities of culture and tourism development, increase investment in creative research and development, and provide better products and services. Culture and tourism enterprises should launch high-end products for international culture and sports events in Beijing. Practitioners need to understand the needs of consumers and provide personalized services to different groups. At the same time, enterprises should gradually improve the innovation mechanism and management model, so as to meet the needs of new market development. Enterprises should pay attention to the communication function of mainstream media and make full use of new media and new technologies. We will vigorously foster new consumption patterns and promote new trends in culture scene consumption.

\section{Acknowledgment}

Supported by: The construction program of innovation team at Beijing Institute of Fashion Technology (BIFTTD201901); The project of the education \& teaching reform at Beijing Institute of Fashion Technology (No.ZDJG-1807). 


\section{References}

1. Bao hongjie, wang shengpeng. Coupling analysis of culture industry and tourism industry [J]. Industrial technology economy,2010,29(08):74-78.

2. $\mathrm{Xu}$ Yanxie. Measurement and evaluation of the integration of culture industry and tourism industry based on the coupling model— Taking Quzhou City, Zhejiang Province as an example[J]. Jiangsu Commercial Forum, 2019(05):66-70.

3. Xu Cuirong, Zhang Guanghai, Lu Fei. Coupling and coordinated development of tourism and culture industries in the provinces along the "Belt and Road" [J]. Journal of China University of Petroleum (Social Science Edition), 2019, 35(04): 85-92 .

4. Wang Qin, Huang Dayong. Measurement and evaluation of the development trend of the integration of tourism industry and culture industry_- Taking Chongqing as an example[J]. Journal of Guangxi Economic Management Cadre College, 2019, 31(02): 68-74+82 .

5. Tang Yong, Xi Yuankai. Coupling Analysis of Culture Industry and Regional Economy in Less Developed Areas - - Taking Jiangxi as an Example[J]. Commercial Economic Research, 2018(23): 150-152.

6. Bi Guohua, Yang Qingyuan, Liu Su. Coupling and coordinated development of China's provincial ecological civilization construction and urbanization[J]. Economic Geography, 2017, 37(01): 50-58. 